Eniko Kiss

Krisztina Kapornai

Ildikó Baji

László Mayer

Ágnes Vetró

\section{Assessing quality of life: mother-child agreement in depressed and non-depressed Hungarian}

Received: 29 April 2008

Accepted: 2 September 2008

Published online: 22 January 2009
E. Kiss, MD $(\varangle) \cdot$ K. Kapornai, MD

I. Baji, MD $\cdot$ L. Mayer, MD

Á. Vetró, MD, PhD

Dept. of Child Psychiatry

University of Szeged

Szeged, Hungary

E-Mail: kiss@gyip.szote.u-szeged.hu
Abstract Purpose An important question in child psychiatry is the agreement between parents and children. We studied motherchild concordance about the quality of life of children (QoL). We hypothesized that mothers of depressed children rate lower QoL than children for themselves while mothers of non-depressed children rate better QoL; that interinformant agreement is higher in the non-depressed sample; and finally that agreement increases with age of the child. Methods QoL of depressed children $(N=248$, mean age 11.45 years, SD 2.02) were compared to that of non-depressed children $(N=1695$, mean age 10.34 years, SD 2.19). QoL was examined by a 7 item questionnaire (ILK). Results Mothers of depressed children rated lower QoL than their children while mothers of nonde- pressed children rated higher QoL than their children. Agreement was low in both samples but higher in the controls. Interinformant agreement was only influenced by depression. Conclusions Our results show that mothers relate more serious negative effects to childhood depression than their children and rate less problems for their non-depressed children compared to selfreports. Mother-child agreement is negatively influenced by depression which further stresses the importance of obtaining reports from the child and at least one parent in order to understand the subjective experiences caused by the illness.

Key words quality of life agreement - depression child - adolescent

\section{Introduction}

The amount of research on the quality of life (QoL) of children has increased greatly over the last few years. The importance of this issue is underlined by the improved life expectancy in children with chronic, life threatening illnesses, the availability of more precise diagnostic tools in child and adolescent psychiatry, the resulting increase in recognition of psychiatric diseases in children and adolescents and the need for systematic assessment of therapeutic interventions. Quality of life as one of the newly incorporated outcome measures offers a unique opportunity to assess and follow the subjective consequences of the factors mentioned above. QoL in general has been defined as a multidimensional concept that encompasses the individual's subjective perception of well-being across all domains of life including physical, social and emotional contexts. The literature differentiates 
health-related QoL [8] from the above which represents the patient's perception of health in various life domains including at least the three areas mentioned above. It refers to how illness affects functioning in different facets of life.

In general it is considered best to ask the opinion of the subject himself about his own QoL. However, the child can be too young or too ill to give adequate information. Parents are frequently asked about their offspring since they are readily available as proxies with a good insight and knowledge about their children. However, it has been widely recognized that child and proxy ratings may not agree on many issues. Parent-child agreement on symptoms of the children is generally low to moderate $[8,10]$. The study of interinformant agreement and factors affecting it remain an important issue in examining children and adolescents. While there are many publications about parent-child agreement on children's quality of life in physical illnesses such as epilepsy [27], asthma [5], cystic fibrosis [11], cancer [20,24, 28, 29, 32], juvenile idiopathic arthritis [2], oral, oro-facial problems [12], there are less in psychiatric illnesses [attention-deficit/ hyperactivity: 3,16$]$ and in general population $[6,26$, 31]. There are only a few that compare ill population to a healthy one in the same study $[5,20,28]$ but their methodology varies greatly, thus making comparison and generalizability difficult.

Overall, these studies support the idea that parents perceive the impact of their child's illness more seriously than children themselves which shows in lower QoL ratings of parents than children. This has been the conclusion of numerous studies of somatically ill children $[11,12,24,32]$ but there are only few studies about psychiatric child populations. Baastiansen et al. [3] investigated children with different psychiatric illnesses and children without any psychiatric diagnosis. They found lower parental QoL ratings in all psychiatric illnesses and in the control sample. In this study, however, psychiatric diagnosis was based only on symptom checklist and thus conclusions regarding specific illnesses are not justified. Klassen et al. [16] investigated children with attention deficit/hyperactivity disorder and found that parents reported significantly worse QoL for four life domains (behavior, mental health, self esteem, and family cohesion) but better QoL for physical functioning while no difference was found between raters in domains like general health, family activities, and social life. No studies were found about QoL agreement in depressed child populations.

Based on the literature we would expect that parents of healthy youngsters rate higher well-being for their children than the offsprings for themselves [6, $28]$. There are some studies on healthy and community samples however that did not find significant differ- ences between child and parent ratings [20,33]. Theunissen et al. [31] in their study of a representative 8 to11-year-old Dutch population found that when the child and the parent both reported low QoL, the child reported relatively higher QoL than the parent. When the child and the parent both reported higher QoL, then the child's scores were lower than the parent's score. This would suggest that when the child is ill (QoL is low), the parent rates the negative effect of the illness higher than the child and when the child is healthy (QoL is high), the parent rates the child's problems lower than child self-report. Naturally, the lack of a gold standard which would define the true QoL of a given child complicates this issue further.

Parent-child agreement in general population samples is generally low to moderate and is dependent on the domain questioned and the method of interviewing [6, 20,33]. Eiser and Morse [10] concluded in their review that there was better agreement between parents and chronically ill children than parents and healthy children. Supporting this result, Russel et al. [28] found better agreement in cancer patients than healthy controls and Robitail et al. [26] showed higher concordance for children with special health care needs and their parents than for healthy parent-child pairs. Levi and Drotar [20], however, found greater discrepancies in the reports of a cancer group. Comparison of agreement on quality of life between depressed children and their parents versus non-depressed children and parents was not reported previously.

The literature is ambiguous concerning variables affecting parent-child agreement about QoL of children. There are conflicting results concerning the effect of the child's age on agreement. Concordance increases with age in some studies in general child population [14, 26] and epileptic samples [27]. In a study of children with oral, dental problems less concordance was reported for older children [12]. Theunissen et al. [31] also found less agreement for 10 to 11-year-olds than 8 to 9 -year-olds in their representative community sample. Child's age was not associated with agreement on QoL in children with cancer [32]. Based on the conflicting results Eiser and Morse [10] concluded in their review that there was no age effect on parent-child concordance of QoL.

The effect of the child's gender on QoL agreement is also ambiguous. Eiser and Morse [10] found no association between gender and mother-child agreement in their review. Jokovic et al. [12] showed better agreement in boys with oral problems and their mothers. Robitail et al. [26] reported higher agreement for girls and parents in a general population sample.

Results concerning the relationship between parent-child agreement in child QoL and the type of the 
domain studied are more straightforward. More observable domains such as school and physical wellbeing [26], behavior [16], illness characteristics such as oral [12] or respiratory symptoms [11] have closer reports while covert domains such as self-esteem, family cohesion [16], mental health [16, 24], and emotional functioning [11] have wider discrepancies. These tendencies have been shown both in somatically ill and general child and adolescent populations. Socio-economical status (SES) seems to have no effect on agreement $[4,31]$.

There are certain methodological considerations for studying agreement. The most frequently used Pearson product-moment correlation coefficient [10] provides information on the covariation among scores but does not indicate absolute agreement. More appropriate statistical methods are intraclass correlation coefficients (ICC) for continuous variables [8] or kappa statistics for categorical ones. It is also useful to examine mean differences between parents' and children's reports [6]. In spite of the above considerations most comparison studies still apply Pearson $r$ statistics. There is a need to compare samples from different backgrounds by more complex methods.

In the present study we hypothesized that parents of depressed children rate lower quality of life for their offspring compared to their children, while healthy children's parents rate higher quality of life than their children for themselves. This is probably due to the increased worry and attentiveness of an ill child's parent compared to the relative carefree attitude of a healthy child's parent. Our second hypothesis was that mother-child agreement on the quality of life of children (QoL) is higher in healthy samples than in depressed ones since there is no anxiety in the mother concerning the child's well-being. Finally, we thought that agreement increases with the age of the child regardless of illness status due to developing insight and increasing ability to share inner feelings and thoughts.

This study fills a gap in our knowledge because literature is scarce in examining parent-child agreement about QoL of children in psychiatric populations. There were no such studies on young depressed patients before. Since this disorder has an increasing prevalence into adolescence with long term impairment and continuity into adulthood, it is important to study the quality of life reported by different raters and its different aspects in this population. The relatively large sample size enables us to study age and gender effects as well. Furthermore, the present study is the first to report on the quality of life and motherchild agreement of an Eastern European depressed child population.

\section{Methods}

Depressed children and their parents were participating in a study of the risk factors of childhood onset depression. Children were recruited through 23 mental health facilities (six of which had both inpatient and outpatient units) across Hungary. Children presenting sequentially at each site were scheduled for assessment if they met the following criteria: 7.0 to 14.9 years old at study entry, not mentally retarded, no evidence of major systemic medical disorder, had available at least one biologic parent and a 7 to 17.9year-old sibling (required by the study's genetic component), and attained a predetermined cut-off score on one of various self- and proxy-reported depressive symptom scales designed for this project. Psychiatric diagnosis was set up by a semi-structured interview (Interview Schedule for Children and Adolescents-Diagnostic version, ISCA-D), a validated and reliable instrument $[15,30]$ based on DSM IV.A two-part psychiatric evaluation was conducted on two separate occasions about 6 weeks apart, by different clinicians. The first part of the evaluation included the Mood disorder section of the ISCA-D and the collection of demographic and anamnestic data from the parents by a structured questionnaire. Subjects also completed self-report forms. Children who fulfilled diagnostic criteria for MDD were scheduled for the second part, a full diagnostic evaluation. Results of the assessments and associated documentation (e.g., psychiatric records) were subjected to final consensus diagnostic procedure [23]. Pairs of senior child psychiatrists trained as Best Estimate Diagnosticians separately reviewed all material and then together derived consensus diagnoses. "Caseness" was determined based on best-estimate consensus. Only those children were included in the present study that had major depressive disorder and were currently in episode. We excluded 11 children because proxy rater was different from the mother and 32 children due to incomplete data. The final sample consisted of $N=248$ children.

Children included in the non-depressed sample $(N=1695)$ were 1 st-8th grade elementary school students from two regions in Hungary whose parents gave written permission to participate. Parents and children received self- and proxy-report forms through the schools. Parents completed the forms at home, children in school during class under supervision. Completion was done anonymously, parentchild pairs were identified by 6-digit code numbers. 5224 families were contacted initially. $68 \%$ of parents agreed to participate, $55 \%$ of the children completed the forms. In the present analysis we excluded those children whose parental informant was not the 
biological mother $(N=274)$, those with chronic somatic illness $(N=72)$ and those who had substantial depressive symptoms $(N=381)$. Information about demographic data, chronic somatic illness and life events was collected by a self-report questionnaire from the mothers. Depressive symptoms were screened by the short version of the Child Depression Inventory [CDI, 17]. It has been shown to be a reliable and useful method for examining children and adolescents $[1,7,19,25]$. We excluded those children who scored above sevenpoints, reported as a clinical cut-off for depression in the literature. Finally, we excluded those with incomplete data $(N=451)$. Children in this group were significantly older (mean age 13.6 years, SD 0.5$)$, there were more boys $(62.9 \%)$, and more divorce in the family $(20.5 \%)$. No difference was found in financial situation, number of children in the family, and maternal years of education. Mean depression symptom score in the excluded group was 4.0 points (SD 2.9) and $19.6 \%$ scored above the clinical cutoff showing clinical level of symptoms. Demographic variables and illness characteristics of the depressed and non-depressed samples can be seen in Table 1. Children in the depressed sample were older there were more boys and maternal education was lower on average than in the control sample.

Quality of life was examined by the Invertar Lebensqualitat Kindern und Jugendlichen (ILK) selfreport questionnaire in both samples. The questionnaire consists of seven items inquiring about QoL during the last week in different domains of life important to children. It was developed by Mattejat et al. and was validated in German and Hungarian samples $[14,21,22]$. The ILK measures quality of life in children aged 6-18, it has child, adolescent and parent versions. The first two versions have similar wording, the parent version is identical to the adolescent one and similar in content to the child version. Scoring is on a 5-point Likert scale, 1 is the best, 5 is the worst QoL. The child version offers faces as scoring options. The questionnaire is easy to answer, it takes 5-10 min to complete, can be read out loud to a child unable to read. Since it is not illness specific, it can be used for both healthy and ill populations making comparison possible. It consists of two additional items for ill populations that inquires about QoL modifying effects of the illness and its therapy.

The items include the domains of school, family, peer relations, alone activities, physical health, mental health and global well-being. Evaluation is possible by the individual items or by total score. The later is calculated by adding the individual scores and subtracting the sum from 35 in order to reverse the direction of the severity of the score. Thus possible total values will fall between 0 and 28,0 being the worst, 28 the best quality of life ratings [14, 21, 22].

Previous studies showed adequate reliability and validity of the questionnaire on a Hungarian sample. Internal consistency was adequate for the parent and adolescent versions (Cronbach $\alpha: 0.78$ and 0.73, respectively) and moderate for the child version
Table 1 Demographic characteristics of the depressed and non-depressed samples

\begin{tabular}{|c|c|c|c|}
\hline Demographic variables & $\begin{array}{l}\text { Depressed sample } \\
(N=248)\end{array}$ & $\begin{array}{l}\text { Non-depressed sample } \\
(N=1,695)\end{array}$ & $P$ \\
\hline \multicolumn{4}{|l|}{ Age of child (years) } \\
\hline Mean (SD) & $11.45(2.02)$ & $10.34(2.19)$ & 0.000 \\
\hline Range (years) & $7-15$ & $7-15$ & \\
\hline \multicolumn{4}{|l|}{ Gender of child } \\
\hline Boys $N(\%)$ & $130(52.4)$ & $744(43.9)$ & 0.012 \\
\hline Girls N (\%) & $118(47.6)$ & $951(56.1)$ & \\
\hline Number of children in family mean (SD) & $3.1(1.4)$ & $2.1(0.9)$ & 0.000 \\
\hline Birth order of child mean (SD) & $2.1(1.2)$ & $1.7(0.9)$ & 0.000 \\
\hline Divorce (\%) & 41.1 & 18.9 & 0.000 \\
\hline \multicolumn{4}{|l|}{ Financial status (\%) } \\
\hline Below average & 35.5 & 14.2 & \\
\hline Average & 56.4 & 55.3 & 0.000 \\
\hline Above average & 8.1 & 30.5 & \\
\hline Education of mother (year) mean (SD) & $11.1(2.7)$ & $13.1(2.3)$ & 0.000 \\
\hline $\begin{array}{l}\text { Hospitalization of mother due to alcohol } \\
\text { or psychiatric problem (\%) }\end{array}$ & 14.9 & 1.2 & 0.000 \\
\hline \multicolumn{4}{|l|}{ Severity of depression (\%) } \\
\hline Mild & 19.3 & - & \\
\hline Moderate & 44.0 & - & \\
\hline Severe & 36.7 & - & \\
\hline No. of depressive episodes mean (SD) & $1.4(0.58)$ & - & \\
\hline Suicidal ideation (\%) & 45.3 & - & \\
\hline Suicidal attempt (\%) & 11.9 & - & \\
\hline Hospitalization (\%) & 31.9 & - & \\
\hline Psychiatric medication (\%) & 60.5 & - & \\
\hline
\end{tabular}


(Cronbach $\alpha$ : 0.66). Test-retest reliability of the total score was also adequate: higher values were found for the parent forms (ICC 0.77) and the adolescent forms (ICC 0.75) and somewhat lower but still acceptable for the child version (ICC 0.67). Test-retest reliability scores of the individual items were the following: parent form 0.54-0.78, adolescent form 0.57-0.71, child form $0.25-0.64$ [14].

Demographic data, life events and information about chronic illness were collected from the parents by a General Information Sheet developed for the study of childhood onset depression [13]. It was used as a self-report questionnaire in the control sample while as a structured questionnaire as part of the diagnostic evaluation in the depressed sample. Years of maternal education served as a proxy for socioeconomic status.

We examined reliability of the self-rated and proxy rated ILK forms first. Then we used multivariate linear regression to test for the effect of individual variables on mother-child agreement. Absolute agreement score was used as the dependent variable. It was computed by subtracting the child's score from the mother's score. The absolute difference score ignores the signs of differences. Its magnitude was assessed by relating it to the maximum possible score. Independent variables in the model were the child's age and gender, presence or absence of depressive illness, and maternal education as a proxy for SES. In order to be comparable with other studies we also computed Pearson $\mathrm{r}$ coefficients and ICC and used the following ratings for comparison: $<0.2$ poor, $0.21-0.4$ fair, $0.41-0.60$ moderate, $0.61-0.80$ substantial, $0.81-$ 1.00 excellent to perfect. Means were compared by paired $t$ test. All data were normally distributed, Kolmogorov-Smirnov tests were significant which justified the use of parametric tests. Associations were regarded significant if $P$ was less than 0.05 .

\section{Results}

Reliability ratings were in the moderate range for both samples and for all raters (Cronbach alphas for depressed children 0.713 , and their mothers 0.715 ; for non-depressed children 0.608 , and their mothers 0.752). The mean values of quality of life scores were lower in the depressed sample than in the non-depressed one regardless of the reporter. Mothers of depressed children rated the QoL of their children significantly lower than children themselves. Mothers of non-depressed children scored significantly higher on the QoL of their offspring than their children. The same direction of differences could be observed in most of the domains. Mothers of depressed children rated lower satisfaction of children in the areas of school, family, peer relations and mental health than their offsprings. No difference was found in the domain of alone activities, while mothers rated better quality of life for physical health than their depressed offspring. Mothers of non-depressed children rated significantly better QoL in the domains of school, alone activity, physical and mental health while worse QoL in family life than their children. No difference was found in the areas of peer relations and global QoL (Table 2).

Multivariate linear regression model showed that the presence of depression in the child was the only significant variable affecting mother-child agreement about the child's quality of life. Age and gender of the child and maternal education did not have a significant effect $(d f=1814, F=25.988, P=0.00$, $\left.R^{2}=0.04\right)$.

Agreement indices of the two samples can be seen in Table 3. Pearson $\mathrm{r}$ correlations and ICC values showed similar associations. Mothers' and children's total scores correlated more closely in the non-depressed sample than in the depressed one. Moderate

Table 2 Quality of life ratings of mothers and children in the depressed and non-depressed samples

\begin{tabular}{|c|c|c|c|c|c|c|}
\hline & \multicolumn{3}{|c|}{ Depressed sample $(N=248)$} & \multicolumn{3}{|c|}{ Non-depressed sample $(N=1,695)$} \\
\hline & Mother & Children & Paired $t$ & Mother & Children & Paired $t$ \\
\hline Total score ${ }^{a}$ & 16.50 & 17.85 & $-4.29 * * *$ & 24.04 & 23.44 & $7.30^{* * *}$ \\
\hline \multicolumn{7}{|c|}{ Domains of quality of life ${ }^{b}$} \\
\hline School & 3.07 & 2.86 & $2.99^{* *}$ & 1.89 & 1.95 & $-3.63^{* * *}$ \\
\hline Family & 2.34 & 2.12 & $3.27^{* * *}$ & 1.34 & 1.28 & $3.67^{* * *}$ \\
\hline Peer relations & 2.50 & 2.14 & $4.7^{* * *}$ & 1.54 & 1.52 & 0.94 \\
\hline Alone activity & 2.13 & 2.25 & -1.47 & 1.56 & 2.06 & $-16.81^{* * *}$ \\
\hline Physical health & 2.05 & 2.23 & $-2.63^{* *}$ & 1.39 & 1.47 & $-3.92^{* * *}$ \\
\hline Mental health & 3.39 & 3.00 & $4.93^{* * *}$ & 1.69 & 1.76 & $-2.89^{* *}$ \\
\hline Global QoL & 3.02 & 2.54 & $6.8^{* * *}$ & 1.54 & 1.52 & 1.3 \\
\hline
\end{tabular}

${ }^{a}$ Total score ratings from 0 to 28 , higher scores represent better quality of life

${ }^{b}$ domain score ratings from 1 to 5 , lower ratings represent better quality of life

${ }^{*} P<0.05$, ** $P<0.01,{ }^{* * *} P<0.001$ 
Table 3 Agreement indices of the depressed and non-depressed samples

\begin{tabular}{|c|c|c|c|c|c|c|c|c|}
\hline & \multicolumn{4}{|c|}{ Depressed sample $(N=248)$} & \multicolumn{4}{|c|}{ Non-depressed sample $(N=1,695)$} \\
\hline & Pearson $r$ & ICC & Abs dif & $\%^{\mathrm{a}}$ & Pearson $r$ & ICC & Abs dif & $\%^{\mathrm{a}}$ \\
\hline Total score & 0.208 & 0.206 & 3.98 & 14 & 0.314 & 0.314 & 2.6 & 9 \\
\hline School & 0.461 & 0.459 & 0.73 & 18 & 0.533 & 0.533 & 0.45 & 11 \\
\hline Family & 0.280 & 0.279 & 0.77 & 19 & 0.212 & 0.211 & 0.38 & 10 \\
\hline Peer relations & 0.222 & 0.221 & 0.85 & 21 & 0.187 & 0.184 & 0.54 & 14 \\
\hline Alone activity & 0.099 & 0.095 & 0.92 & 23 & 0.080 & 0.071 & 0.93 & 23 \\
\hline Physical health & 0.184 & 0.182 & 0.75 & 19 & 0.190 & 0.186 & 0.47 & 12 \\
\hline Mental health & 0.127 & 0.120 & 0.99 & 25 & 0.202 & 0.201 & 0.64 & 16 \\
\hline Global QoL & 0.151 & 0.144 & 0.89 & 22 & 0.159 & 0.159 & 0.51 & 13 \\
\hline
\end{tabular}

ICC Intraclass correlation, Abs dif Absolute difference score, mother-child score, QoL quality of life

aPercent of maximum possible difference

associations could be observed in satisfaction with school regardless of illness status. The rest of the correlations were poor to fair. The difference between raters in the depressed sample was greater than in the non-depressed sample (3.98 or $14 \%$ vs. 2.6 or $9 \%$, respectively). Exploring differences in the individual domains in the depressed sample the highest disagreement was seen in the area of mental health and global rating of well-being. Interestingly, the absolute difference in the area of alone activity was the same $(23 \%)$ in both samples. Besides that difference, the rest of the domains showed larger inter-rater differences in the depressed sample (range from 18 to 25\%) than in the non-depressed one (range from 11 to $16 \%$ ).

\section{Discussion}

Depressed and non-depressed child populations were compared in the present study concerning their quality of life and the agreement between self and proxy ratings. The results add to current knowledge about quality of life issues and inter-informant agreement of depressed versus non-depressed youth. There has not been such a study published before on an Easter European child population.

In accordance with our hypothesis parents of depressed children rated lower quality of life overall and in most domains than their children. Higher parental ratings of the negative effect of illness compared to the child has been shown in various somatic disorders, in attention-deficit/hyperactivity [16] and in psychiatric outpatient population [3]. In Baastiansen's study patients suffering from mood disorder were included in the sample but diagnosis was based on a symptom checklist. The depressed population in our sample was diagnosed by a more precise semistructured interview based on DSM IV criteria. In a study of quality of life of epileptic children Ronen et al. [27] showed that while parents equally considered present and future concerns caused by the illness, children considered present concerns far more important than future ones. This finding might explain the difference in the opinion of the parent and that of the sick child about quality of life with the illness. They also suggest that the burden of care giving of the parent might cause misjudgment of the child's problems. It is also possible that the child is unable to fully comprehend the impact of illness on his or her life. Parents of non-depressed children in our study rated better quality of life for their children that children for themselves. Levi and Drotar [20] did not find significant differences between the opinions of children and their parents in a healthy control group. The sample size in this study was very small which can explain the differences in their results compared to ours. In a more recent study Russel et al. [27] found better QoL reported by parents than children in a healthy comparison sample in 8 out of 10 domains of life. Our results support the tendency of parents to relate more serious negative effects to depressive disorder than their children themselves and to undervalue their non-depressed offsprings' problems compared to the children. On the one hand these findings underline the importance of parental education and guidance in chronic pediatric conditions besides the medical treatment of the child, and on the other the need for surveillance and prevention based on children's opinion in the community.

Mother-child agreement is studied by various methods in the literature. We used the most frequently applied but limited Pearson correlation and the intraclass correlation coefficient. Agreement was better in the non-depressed sample by all methods. This contradicts previous results on QoL concordance in physically ill populations. It is possible that a somatic condition shows more observable, better understood negative consequences and therefore more reliably grasped by the parents, while the effects of psychiatric illnesses are less straight forward, more covert and thus less observable. This would explain why agreement is better in chronic physical illnesses 
and worse in psychiatric diseases compared to healthy populations while having similarly lower levels of parental QoL ratings compared to child self-reports in both conditions.

The highest agreement in both samples was in the domain of school life. It has been known to be among the most observable domains and also one about which the opinion of an outsider, the teacher, is readily available. QoL concerning school life proved to be the most highly agreed domain in other studies as well $[24,26]$.

Absolute differences helped us to investigate further. An important finding of this study is that QoL of mental health was the most controversial domain in the opinions of depressed child-mother dyads. It might even offer an explanation for the greater disagreement in the depressed sample compared to the non-depressed one, major depression being one of the most important factors influencing mental health. Mothers of depressed children probably do not understand the internal states of their children and receive limited information from their ill children. It was shown previously that mental health is the domain that correlates most closely to global quality of life in a community sample using the same instrument [14]. Satisfaction with activities and time spent alone shows similarly high disagreement in both samples; therefore it is not specific to the depressed population.

The effect of age on agreement was not significant in our sample but there was a tendency for increased concordance as children got older. In Robitail's study [26] involving an European community sample agreement was higher for adolescent-parent dyads than for child-parent dyads. However, age was used as a dichotom variable in this study. In the other two publications examining psychiatric samples the effect of age on agreement was not investigated $[3,16]$. Eiser and Morse [10] concluded in their review that age did not have an effect on mother-child concordance about QoL of children. Similar results emerged concerning the effect of gender on agreement. There were no differences between boys and girls and their mothers' agreement in our sample. The presence of depression was the only factor which considerably and significantly influenced - more precisely decreased agreement between mothers and children about QoL of children.

The present study has some limitations. Interview circumstances were not the same in the two samples. Depressed children and their mothers were interviewed by trained interviewers using a semi-structured psychiatric interview. Following the interview parents and children self-rated the QoL forms separately. Non-depressed children self-rated the same forms in a school setting; their parents filled the questionnaires at home. It is possible that circumstances of the interview (length, involvement, feelings toward interviewer) influenced the answers of the interviewees during the self-report [33]. However, it is impossible in real-life testing to ensure the exact same circumstances in different populations. At the same time the same forms and the same methods were used in both samples to help the comparison of data.

The lack of a "gold standard", that is an undoubtly reliable and adequate pool of information about the illness specifics of the child, is a further limitation of the study of agreement in child psychiatry. Even if such a standard did exist, untrained informants probably use different thresholds and have different abilities, skills and judgment biases which influence their opinions. Therefore, reports of different informants must be compared to each other without exact knowledge of their validity. For this reason the study of inter-informant agreement and factors influencing it are especially important.

It has been shown in previous studies that parents' own well being also influences their opinion about their child's quality of life. Specifically, parental depression [32], parental stress [32, 34] and parental QoL [6] were studied. However, their potential role in affecting agreement has not been certified. It is a limitation of our study that we had no valid information about mothers' own QoL or depression levels. There is a clear need to carry on the evaluation of factors related to differences in self and proxy ratings and their agreement in child psychiatry and pediatrics.

Since the above examined variables explained only a small variance of disagreement, evaluation of other possible contributing factors should continue. A very important clinical question is how many or rather what kinds of raters are necessary in order to collect clinically useful amount of valid information. One possibility is conceptualizing the contexts and perspectives that influence the behavior and identify at least 3 informants based on this model [18]. As a matter of fact, informant discrepancies themselves may be conceptualized as a useful component in a clinical setting taking into consideration the origin of discrepancies [9].

\section{Conclusion}

Our results underline the need of assessing at least one parent beside the child when inquiring about the QoL. Based on our results we can conclude that proxy rating is equally important in children regardless of age and gender. It is important for clinicians to keep in mind that the already low parent-child agreement 
is further decreased by chronic psychiatric conditions like major depression. The examiner should be knowledgeable of the effect of the child's physical and psychological state on agreement when questioning parents and children.

Major depression as a chronic psychiatric condition decreases the quality of life of children significantly, lowers inter-rater agreement and the difference is the greatest in the domain of mental health. It should be the aim of future studies to investigate whether the same is true for quality of life issues in other psychiatric disorders.

Acknowledgement This work was partly supported by National Institute of Mental Health Program Project grant, MH 56193.

\section{References}

1. Allen EC, Combs-Orme T, McCarter R, Grossman LS (2000) Self-reported depressive symptoms in school-age children at the time entry into foster care. Amb Child Health 6:45-57

2. April KT, Feldman DE, Platt RW, Duffy CM (2006) Comparison between children with juvenile idiopathic arthritis (JIA) and their parents concerning perceived quality of life. Quality of Life Research 15:655-661

3. Baastiansen D, Koot HM, Ferdinand RF, Verhulst FC (2004) Quality of life in children with psychiatric disorders: self-, parent, and clinician report. J Am Acad Child Adolesc Psychiatry 43:221230

4. Cavallo F, Zambon A, Boraccino A, Raven-Sieberer U, Torsheim T, Lemma P, The HBSC Positive Health Group (2006) Girls growing through adolescence have a higher risk of poor health. Qual Life Res 15:1577-1585

5. Coq EM, Boeke AJ, Bezemer PD, Colland VT, Eijk JT (2000) Which source should we use to measure quality of life in children with asthma: the children themselves or their parents? Qual Life Res 9:625-636

6. Cremeens J, Eiser C, Blades M (2006) Factors influencing agreement between child self-report and parent proxy-reports on the Pediatric Quality of Life Inventory 4.0 (PedsQL) generic core scales. Health Qual Life Outcomes 4:58

7. Davanzo P, Kerwin L, Nikore V, Esparza C, Forness S, Murelle L (2004) Spanish translation and reliability testing of the child depression inventory. Child Psychiatry Hum Dev 35:7592

8. De Civita M, Regier D, Alamgir AH, Anis AH, FitzGerald MJ, Marra CA (2005) Evaluating health-related quality-of-life studies in pediatric populations. Pharmacoeconomics 23:659-685

9. De Los Reyes A, Kazdin AE (2005) Informant discrepancies in the assessment of childhood psychopathology: a critical review, theoretical framework, and recommendations for further study. Psychol Bull 131(4):483-509
10. Eiser C, Morse R (2001) Can parents rate their child's health-related quality of life? Results of a systematic review. Qual Life Res 10:347-357

11. Havermans T, Vreys M, Proesmans M, de Boeck C (2006) Assessment of agreement between parents and children on health-related quality of life in children with cystic fibrosis. Child Care Health Dev 32:1-7

12. Jokovic A, Locker D, Stephens M, Guyatt G (2003) Agreement between mothers and children aged 11-14 years in rating child oral health-related quality of life. Community Dent Oral Epidemiol 31:335-343

13. Kapornai K, Gentzler AL, Tepper P, Kiss E, Mayer L, Tamás Zs, Kovacs M, Vetró A, The International Consortium for Childhood-Onset Mood Disorders (2007) Early developmental characteristics and features of major depressive disorder among child psychiatric patients in Hungary. J Affect Disord 100(1-3):91-101

14. Kiss E, Baji I, Mayer L, Skultéti D, Benák I, Vetró Á (2007) Validity and psychometric properties of the Quality of Life Questionnaire in a Hungarian child population. Psychiatria Hungarica 22(1):33-42

15. Kiss E, Gentzler AM, George C, Kapornai K, Tamás Zs, Kovacs M, Vetró Á (2007) Factors influencing mother-child reports of depressive symptoms and agreement among clinically referred depressed youngsters in Hungary. J Affect Disord 100(1-3):143151

16. Klassen AF, Miller A, Fine S (2006) Agreement between parent and child report of quality of life in children with attention-deficit/hyperactivity disorder. Child Care Health Dev 32:397-406

17. Kovacs M (1992) Children's Depression Inventory Manual. Multi-Health systems, North Tonawanda,

18. Kraemer HC, Measelle JR, Ablow JC, Essex MJ, Boyce WT, Kupfer DJ (2003) A new approach to integrating data from multiple informants in psychiatric assessment and research: mixing and matching contexts and perspectives. Am J Psychiatry 160(9):15661577
19. Larson B, Melin L (1992) Prevalence and short-term stability of depressive symptoms in school children. Acta Psychiatr Scand 85:17-22

20. Levi RB, Drotar D (1999) Health-related quality of life in childhood cancer: discrepancy in parent-child reports. Int J Cancer 12:58-64

21. Mattejat F, Jungmann J, Meusers M, Moik C, Nölkel P, Schaff C (1988) Das inventar zur erfassung der lebensqulitat bei kindern und jugendlichen (ILK)-eine pilotstudie. Zeitschrift für Kinder- und Jugendpsychiatrie und Psychotherapie 26:174-182

22. Matttejat F, Remschmidt H (1988) Zur erfassung der lebesqualitat bei psychisch gestörten kindern und jugendlichen-eine übersicht. Zeitschrift für Kinder- und Jugendpsychiatrie und Psychotherapie 26:183-196

23. Maziade M, Roy MA, Fournier JP, Cliché D, Merette C, Caron C (1992) Reliability of best-estimate diagnosis in genetic linkeage studies of major psychoses: results from the Quebec pedigree studies. Am J Psychiatry 149:16741686

24. Parsons SK, Barlow SE, Levy SL, Supran SE, Kaplan SH (1999) Health-related quality of life in pediatric bone marrow transplant survivors: according to whom? Int J Cancer Suppl 12:4651

25. Poli P, Sbrana B, Marcheschi M, Masi G (2003) Self-reported depressive symptoms in a school sample of Italian children and adolescents. Child Psychiatry Hum Dev 33:209-226

26. Robitail S, Simeoni MC, Erhart M, Ravens-Sieberer U, Bruil J, Auquier P, The European Kidscreen Group (2006) Validation of the European KIDSCREEN-52 pilot test health-related quality of life questionnaire: first results. J Adolesc Health 39:596.e1596.e10

27. Ronen GM, Streiner DL, Rosenbaum P, The Canadian Pediatric Epilepsy Network (2003) Health-related quality of life in children with epilepsy: development and validation of self-report and parent-proxy measures. Epilepsia 44:598-612 
28. Russel KM, Hudson M, Long A, Phipps S (2006) Assessment of health-related quality of life in children with cancer. Cancer 106:2267-2274

29. Sawyer M, Antoniuo G, Toogood I, Rice M (1999) A comparison of parent and adolescent reports describing the health-related quality of life of adolescents treated for cancer. Int J Cancer Suppl 12:39-45

30. Sherill JT, Kovacs M (2000) Interview schedule for children and adolescents (ISCA). J Am Acad Child Adolesc Psychiatry $39: 67-75$
31. Theunissen NC, Vogels TG, Koopman HM, Verrips GH, Zwinderman KA, Verloove-Vanhorick SP, Wit JM (1998) The proxy problem: child report versus parent report in health-related quality of life research. Qual Life Res 7:387-397

32. Vance YH, Morse RC, Jenney ME, Eiser C (2001) Issues in measuring quality of life in childhood cancer: measures, proxies, and parental mental health. J Child Psychol Psychiatry 42:661-667

33. Verrips GH, Vogels AG, den Ouden AL, Paneth N, Verloove-Vanhorick SP (2000) Measuring health-related quality of life in adolescents: agreement between raters and between methods of administration. Child Care Health Dev 26(6):457-469
34. White-Koning M, Arnaud C, Dickinson HO, Thyen U, Beckung E, Fauconnier J, McManus V, Michelsen SI, Parkes J, Parkinson K, Schirripa G, Colver A (2007) Determinants of child-parent agreement in quality-of-life reports: a European study of children with cerebral palsy. Pediatrics 120(4):e804-e814 